\section{Meningitis aséptica lúpica secundaria a ibuprofeno}

\section{Sr. Director:}

El lupus eritematoso sistémico (LES) es una enfermedad multisistémica que puede afectar a diferentes órganos y se puede presentar con múltiples formas de inicio ${ }^{1}$. Su incidencia y prevalencia ha aumentado debido a un mejor reconocimiento de los casos leves y a la mayor supervivencia de la enfermedad en nuestros días ${ }^{2}$, papel en el que el médico de Atención Primaria juega un papel muy importante. La meningitis aséptica lúpica es una entidad poco frecuente. A continuación, presentamos un caso de meningitis aséptica en una paciente con LES secundaria a ibuprofeno.

Se trata de una mujer de 34 años de edad, fumadora de 20 cigarros/día y que presenta un LES, el cual debutó con neutropenia y febrícula mantenida hace 6 años. Actualmente, tiene un satisfactorio curso clínico en tra- tamiento con hidroxicloroquina 3 $\mathrm{mg} / \mathrm{kg} / 48$ horas. Acude al servicio de urgencias de nuestra área básica de salud por tos seca de 3 días de evolución. La exploración física por aparatos es normal, excepto un leve dolor a la palpación en hemiabdomen inferior. Ante los hallazgos encontrados en la exploración abdominal, se reinterroga a la paciente y refiere dismenorrea de 2 días de evolución. Orientándose el cuadro de tos irritativa y dismenorrea, se pauta tratamiento sintomático (abstención tabáquica y abundante ingesta de líquidos) e ibuprofeno $600 \mathrm{mg} / 8$ horas. Dos días después es ingresada en el centro de referencia por síndrome meníngeo y fiebre elevada (hasta $40^{\circ}$ ), donde la punción lumbar muestra un líquido cefalorraquídeo con hiperproteinorraquia y cultivos negativos, los hemocultivos son negativos y las pruebas de imagen craneales (TAC y RMN) son estrictamente normales. Con el diagnóstico de meningitis aséptica lúpica secundaria a ibuprofeno, puesto que no hay ningún cuadro vírico previo y dado el antecedente de la pres- cripción del fármaco desde hacía 48 horas, se le retira éste, se le instaura tratamiento con bolus de 6-metilprednisolona durante 4 días para seguir con terapia descendente durante un mes y se le aumenta a hidroxicloroquina a 4 $\mathrm{mg} / \mathrm{kg} / 24$ horas, teniendo una evolución satisfactoria. Dos meses después del cuadro, la enferma se encuentra totalmente asintomática tanto de la meningitis aséptica como del LES con hidroxicloroquina $4 \mathrm{mg} / \mathrm{kg} / 48$ horas.

Las manifestaciones neuropsiquiátricas son relativamente frecuentes en el LES, diagnosticándose en un 50-60\% de los casos (Tabla I). La etiología de la meningitis aséptica lúpica está basada en procesos víricos concomitantes a la enfermedad de base y en la asociación a fárma$\cos ^{3}$. Se han propuesto dos modelos etiopatogénicos cuando es secundaria a la administración de ciertos medicamentos: irritación directa de las meninges por administración intratecal del fármaco; secundaria a una reacción inmunológica de hipersensibilidad tardía semejante a las de tipo III o 


\section{Tabla I}

\section{MANIFESTACIONES NEUROPSIQUIÁTRICAS EN EL LES}

Trastornos psiquiátricos, déficits cognitivos y estados confusionales agudos

Anomalías cognitivas

Estados confusionales agudos

Psicosis

Trastornos del estado de ánimo

Ansiedad

Síndromes neurológicos del sistema nervioso central

Convulsiones

Cefalea (como migraña e hipertensión intracraneal benigna)

Enfermedad cerebrovascular (isquémica y/ o hemorrágica)

Síndrome desmielinizante

Trastornos del movimiento (corea)

Mielopatía

Meningitis aséptica

Síndromes neurológicos del sistema nervioso periférico

Polirradiculoneuropatía desmielinizante aguda inflamatoria (Guillain-Barré)

Trastornos autonómicos

Mononeuropatía única/ múltiple

Miastenia gravis

Neuropatías craneales

Plexopatía

Polineuropatía tipo IV. Los principales fármacos que pueden producir meningitis aséptica en el LES se describen en la tabla $\mathrm{II}^{4}$. El hecho que los antiinflamatorios no esteroideos y los antibacterianos sean los agentes causales de la mayor parte de estos casos responde probablemente a que los primeros configuran la primera línea de estrategia terapéutica a seguir en el LES ${ }^{5}$ y los segundos a que las infecciones tienen una elevada incidencia en esta enferme$\mathrm{dad}^{3}$, por lo que se utilizan con cierta frecuencia. Es importante destacar que esta entidad no sólo se produce en esta patología, sino que también ha sido descrita en otras enfermedades del tejido conectivo (artritis reumatoide ${ }^{6}$, enfermedad de Kikuchi ${ }^{7}$, etc.), hecho que potenciaría el segundo modelo etiopatogénico. El diagnóstico de meningitis aséptica lúpica secundaria a cualquier fármaco es siempre de exclusión y se debe investigar siempre primero una etiología infecciosa, que el paciente no esté en un brote agudo de actividad de la enfermedad y descartar alteraciones neurológicas previas. Por lo general, los hallazgos biológicos y los exámenes radiológicos suelen ser normales en la meningitis aséptica ${ }^{8}$, estando alterados, sin embargo, en las otras situaciones. La evolución suele ser satisfactoria con la retirada precoz del fármaco, administación de bolus endovenosos de glucocorticoides durante un periodo corto de tiempo (3-7 días) para seguir una pauta descendente por vía oral y reajuste de la medicación de base del LES que tome el paciente. No suele causar secuelas a corto, medio ni a largo plazo ${ }^{4}$. El médico de Atención Primaria, al igual que en el diagnóstico de las formas de presentación leves del LES, juega un papel primordial para la prevención de episodios recurrentes de meningitis aséptica lúpica secundaria a un determinado fármaco, evitando la nueva administración de éste. 


\section{López-Marina, G. Pizarro Romer o*, N. Costa Bar daji}

Residente de $3^{\circ}$ año de Medicina Familiar y Comunitaria. *Médico de Familia. Área Básica de Salud Badalona 6-Llefià (Unidad Docente de Medicina Familiar y Comunitaria del Barcelonés Nord-Maresme). Barcelona

\section{BIBLIOGRAFÍA}

1. Vilardell M, Ordi J. Enfermedades difusas del tejido conjuntivo. Lupus eritematoso sistémico. En: FarrerasRozman, edición. Medicina interna. $12^{\mathrm{a}}$. ed. Barcelona: Ediciones Doyma SA, 1992; 996-1003.

2. Uramoto KM, Michet CJ, Thumboo J, Sunku Y, C'Fallon WM, Gabriel SE, et al. Trends in the incidence and mortality of systemic lupus erythematosus 1950-1992. Arthritis Rheum 1999; 42: 46-50.

3. Rodríguez GA, Zea MA. Etiopatogenia y manifestaciones clínicas del lupus eritematoso sistémico. En: Alonso RA, Álvaro-Gracia AJ, Andreu SJ, Blanch RJ, Collantes EE, Cruz MJ, et al, edición. Manual S.E.R. de las enfermedades reumáticas. $3^{\text {a }}$. ed. Madrid: Editorial Médica Panamericana, S.A., 2000; 287-300.

4. Jolles S, Sewell WA, Leighton C. Drug-induced aseptic meningitis: diagnosis and manegement. Drug Saf 2000; 22: 215-26.

5. Rodríguez-Valverde V, Blanco AR. Lupus eritematoso sistémico. Tratamiento. En: Alonso RA, ÁlvaroGracia AJ, Andreu SJ, Blanch RJ, Collantes EE, Cruz MJ, et al, edición. Manual S.E.R. de las enfermedades reumáticas. $3^{\mathrm{a}}$. ed. Madrid: Editorial Médica Panamericana, S.A., 2000; 300-6.

6. Horn AC, Jarrett SW. Ibuprofeninduced aseptic meningitis in rheumatoid arthritis. Ann Pharmacother 1997; 31: 1009-11.

7. Sierra ML, Vegas E, Blanco-González JE, González A, Martínez P, Calero MA. Kikuchi's disease with multisystemic involvement and adverse reactions. Pediatrics 1999; 104: 324.

8. Moris G, Garcia-Monco JC. The challenge of drug-induced aseptic meningitis. Arch Intern Med 1999; 159: 1185-94. 